\title{
ESTUDO CRÍTICO-COMPARATIVO SOBRE APLICATIVOS DE STORYTELLING PARA TABLETS
}

\author{
Pamela Torres Maia Beckman da Cruz \\ Universidade Federal do Maranhão \\ pam.tmaia@gmail.com \\ Carlos de Salles Soares Neto \\ Universidade Federal do Maranhão \\ csallesneto@gmail.com
}

\begin{abstract}
Resumo: $\mathrm{O}$ ato de contar histórias remonta ao início da humanidade com as mais diversas formas de interação. Atualmente com o surgimento dos dispositivos móveis como tablets e celulares temos uma nova mídia de interação através de aplicativos. Eles podem ser utilizados para o ato de contar histórias, também chamado na literatura de storytelling. Em cada um desses aplicativos desses é possível identificar elementos visuais e de interação em comum, criando uma categoria específica para os mesmos. Este artigo se propõe a realizar um estudo crítico-comparativo dessa categoria de aplicativos, para que posteriormente seja possível o desenvolvimento de uma ferramenta de autoria que contemple todas as necessidades de interface e interação com o usuário.
\end{abstract}

Palavras-chave: mídia, storytelling, tablet, aplicativos.

\section{INTRODUÇÃO}

$\mathrm{O}$ ato de contar histórias remonta aos primórdios da humanidade e a criação da linguagem, quando nossos ancestrais sentiram a necessidade de perpetuar suas ações, aventuras e conhecimentos acerca de sua vida e de tudo que o cercava no cotidiano.

Atualmente com o surgimento de dispositivos móveis, como tablets e celulares, temos uma nova mídia de interação através de aplicativos. Esses aplicativos podem ser utilizados para o ato de contar histórias, também chamado na literatura de storytelling.

Partindo dessa análise, o presente artigo em seu primeiro momento aborda uma breve conceitualização do que é uma storytelling, considerada no mesmo como "história digital interativa", e sua repercussão na atualidade. O trabalho apresenta também um catálogo sobre os aplicativos estudados, com sua descrição e análise crítica. Já, em um terceiro momento, acontece um levantamento dos padrões de interação e um quadro comparativo das aplicações analisadas em cada aplicativo. Para finalizar o estudo, são feitas considerações a partir da análise de cada aplicativo e 
dispositivo, com opiniões sobre alterações que poderiam ser realizadas para melhoria dos mesmos.

Este artigo tem por objetivo fazer um estudo crítico-comparativo dos aplicativos mais utilizados por usuários de tablets atualmente, quais suas características e os padrões interativos recorrentes; partindo de uma breve descrição e realizando uma análise sobre os mesmos, para que posteriormente seja possível o desenvolvimento de uma ferramenta de autoria para esse tipo de aplicativo.

Para realização da pesquisa, no período de abril de 2014, foram utilizados dois dispositivos móveis, sendo estes, tablets de marcas e modelos consolidados no mercado: o IPad Mini, da Apple, que usa o sistema operacional iOS, e o Galaxy Tab 2 10.1, da Samsung, que utiliza o sistema operacional Android 4.1.2. O resultado é um estudo critico-comparativo de diversos aplicativos.

\section{STORYTELLING}

Originária da expressão inglesa "Tell a story", que significa "contar uma história", o termo "storytelling", se relaciona a uma narrativa e a capacidade de contar uma história através de palavras e recursos audiovisuais, sendo esta uma história improvisada ou trabalhada; e considerada um importante meio de propagação de valores e regras da cultura popular. Uma storytelling também pode ser nomeada por 'histórias digitais interativas' (MASSAROLO, 2013).

Quanto ao surgimento da storytelling, MASSAROLO (2013) e COGO (2012) relatam que não se pode afirmar com precisão uma data de criação da mesma, pois relata-se que ela vem dos primórdios da história da humanidade se relacionando a criação da linguagem e a necessidade de nossos ancestrais de perpetuar suas ações, aventuras, cultura e conhecimentos da sua vida e de seu cotidiano.

Para a construção de uma storytelling é necessário identificar elementos essenciais a sua composição, como: o estilo da abordagem, o personagem foco, a interatividade, as emoções que é capaz de despertar, o apelo sentimental, o diálogo, o roteiro com começo/meio/fim, a promoção do clímax, a necessidade de um conflito e sua identificação com o público (COGO, 2012).

Atualmente a storytelling é encontrada nas mais diversas áreas de conhecimento, sendo desenvolvida e aplicada a alguma ferramenta, ou, a mesma pode ser considerada uma ferramenta de compartilhamento de conhecimento. Chamada de Transmidia Storytelling considera-se como transmissão de uma história através de diferentes tipos de mídia voltada a diferentes públicos (MASSAROLO, 2013).

De acordo com MASSAROLO (2013), o termo 'Storytelling transmídia', se originou com Henry Jenkins, pensando no 'ato de contar histórias através de várias mídias'. Para o autor, o termo Storytelling possui dois níveis de significado: no primeiro se refere ao termo generalizado de narrativa como um meio de transmissão da história. O segundo se refere a uma parte da narrativa, à história como a diferenciação entre a sequência em que os eventos são apresentados ao leitor e a 'real' ordem cronológica dos eventos reconstruídos pelo leitor. Além disso, na storytelling, também tem que se atentar à dicotomia entre fábula e trama. O termo também pode ser encontrado em português como 'narrativa transmídia'.

Ao longo da história, o sentido etimológico da palavra storytelling (story história; telling - contar), ou seja, o ato de 'contar histórias', adquiriu novos sentidos, assumindo variados graus de importância e diferentes significados. 


\begin{abstract}
As histórias sempre existiram e é por meio delas que não somente nos é apresentado os mistérios do mundo, como também transmitimos nosso legado cultural para as gerações futuras. $O$ ato de contar histórias remonta à própria história da humanidade, quando narradores (storytellers) sentados ao redor de fogueiras trocavam experiências entre si sobre os embates travados com as forças desconhecidas da natureza. A função do narrador era de ativar crenças e valores, fornecer sentidos aos acontecimentos através do relato de histórias. Esses relatos não se limitavam ao universo das experiências individuais, servindo para formular hipóteses e indagações sobre o nosso próprio destino. (MASSAROLO, 2013 - p.338)
\end{abstract}

Observa-se então, que este termo se relaciona a arte de contar histórias que é específico das plataformas midiáticas, pressupondo a interatividade e o compartilhamento de histórias. O termo se apresenta como uma ferramenta que traz consigo uma noção de 'complexidade narrativa'. Esses fatores são responsáveis pela criação de estratégias que modificaram a economia discursiva e alteraram o status do storytelling e o lugar que o mesmo ocupava na sociedade contemporânea.

Segundo MASSAROLO (2013), em seu artigo "Storytelling transmídia: Narrativa para multiplataformas", a Storytelling transmídia se transformou, para as grandes empresas midiáticas da atualidade em uma das principais estratégias de entretenimento nas multiplataformas, pois, segundo o autor, estimula 0 compartilhamento de informações e o desenvolvimento de modelos de negócios baseados na cultura participatória, priorizando o diálogo entre produtores e consumidores, ou seja, melhora a relação entre o produto e o usuário. Neste contexto, ela se diferencia das demais storytelling pela criação de universos narrativos expandidos e pelo alto grau de complexidade narrativa, que se originou após desenvolvimento de tecnologias de reprodução e armazenamento de dados, vistas em plataformas de reassistência, como: Smart TV, smartphones e tablets, entre outros.

Assim, podemos considerar que MASSAROLO (2013) dialoga em seu artigo que, 'O storytelling contemporâneo atende as demandas da lógica comercial de exploração dos itens associados ao composto da franquia, se tornando um novo paradigma do entretenimento nas multiplataformas do ecossistema midiático, tendo a capacidade de fazer uma narrativa transmidiar-se através de diferentes plataformas e, por outro, de se tornar uma narrativa das marcas, a serviço das demandas da lógica comercial de exploração dos itens associados ao composto da franquia'.

Após esta breve conceitualização do que é uma storytelling, ou história digital interativa, direciono o estudo é direcionado a um levantamento dos aplicativos que estão sendo mais utilizados por usuários de tablets atualmente, suas características e os padrões interativos encontrados; realizando uma breve descrição e uma crítica comparativa sobre os mesmos.

\title{
3. CATÁLOGO DE APLICAÇÕES
}

Inicialmente é proposta uma análise comparativa dos tablets utilizados para realização deste estudo no que se relaciona a um ambiente voltado às histórias interativas digitais em suas lojas de aplicativos.

No caso do dispositivo da marca Apple, o seu sistema operacional apresenta uma loja de aplicativos, a App Store, com uma sessão voltada especialmente às histórias interativas, onde na mesma podemos encontrar subseções que dividem os aplicativos de histórias interativas em categorias, sendo estas: destaques, lançamentos 
ou nome. A mesma também conta com uma grande variedade de aplicativos, porém grande parte possui um custo que variam de 0,99 a 9,99 dólares e poucos são os disponíveis gratuitamente em sua grade; além disso a maioria dos aplicativos disponibilizados pela empresa, mesmo sendo a loja de entrada voltada ao idioma de referência do usuário, apresentam-se na língua inglesa, limitando assim os usuários dos mesmos, já que a marca, seus dispositivos e sua loja de aplicativos estão disponíveis em diversos países com culturas e línguas diferentes.

Se voltando ao dispositivo da Samsung, com sistema operacional Android, o mesmo dispõe de uma loja, Play Store, disponibilizada pela empresa Google, também responsável pelo desenvolvimento do sistema operacional, que infelizmente não apresenta uma sessão específica aos aplicativos voltados as histórias interativas. A mesma apesar de apresentar-se de acordo com a linguagem e cultura do país que está sendo alocada, peca no fato de não ter uma sessão ou categoria voltada a esse tipo de aplicativo ou mesmo relacionado a histórias de um modo geral. Com isso, para localizar aplicativos desse gênero é necessário realizar uma busca por "contos infantis" ou "história para crianças"; o que pode se considerar como uma falta de organização da biblioteca disponível na Play Store. Se deve relatar ainda que poucos são os aplicativos encontrados na loja realizando este tipo de busca. Contudo, todos os aplicativos encontrados estavam disponíveis gratuitamente aos usuários do dispositivo.

Feito esse comparativo, discorro a seguir um catálogo com os três aplicativos mais requisitados e disponibilizados gratuitamente em ambos os dispositivos utilizados para realização desta pesquisa.

\subsection{Aplicativos disponíveis no IPad Mini (Apple)}

\subsubsection{Alice for the IPad}

Desenvolvido pela Atomic Antelope, o Alice for the IPad foi aclamado pela crítica especializada como o melhor aplicativo voltado às histórias interativas, este foi considerado um dos primeiros livros interativo inteligente disponibilizado em um tablet, o que alavancou o vislumbre pela literatura digital e se tornou um exemplo a ser seguido para a melhoria da literatura infantil digital.

O Alice for the IPad (Figura 1a) foi também considerado por especialistas como a abertura para a nova geração de livros digitais, o inicio de mudanças para desenvolvimento de livros disponíveis nas mídias digitais; e a 'reinvenção' da leitura, por incorporar animação aos textos.

Ao analisar o aplicativo, nota-se primeiramente que o mesmo disponibiliza de duas versões do texto a ser lido: uma no modo resumido e, ao lado, o texto original para os leitores que tiverem mais tempo e quiserem conhecer a história na íntegra; o mesmo ainda apresenta páginas digitais com cenas e imagens animadas, onde estas se movem de acordo com a manipulação do tablet através do acelerômetro.

Com isso, por exemplo, em uma página é possível mover o dispositivo e fazer Alice crescer ou encolher; ou em outra página, balançar o relógio de bolso do Coelho Branco, como vemos na Figura 1b; entre outras interações disponíveis, sem no entanto retirar o visual clássico da história, com suas páginas e ilustrações originais que imitam as produções literárias antigas impressas em papel e o fato de possibilitar ao usuário mudar de página como se estivesse mudando a página de um livro impresso. 
Vale ressaltar que, apesar de todo arcabouço interativo, o Alice for the IPad ainda apresenta uma interface de fundo fixa e que somente elementos dispostos a frente desta é que interagem com o usuário. E ainda existem elementos que poderiam ser colocados no aplicativo, mas que não foram disponibilizados, como, por exemplo, uma narrativa, por questões de acessibilidade.

O aplicativo ainda tem algumas implicações específicas para uso, como a de compatibilidade, pois é compatível somente com o dispositivo da Apple e requer um sistema operacional iOS 3.2 ou posterior. Outro embate é o fato de ser encontrado somente na língua inglesa, o que limita o número de usuários do aplicativo. Segundo dados da fabricante, tendo sua última atualização realizada em 01/12/2011, seu tamanho é de $41,0 \mathrm{Mb}$ e sua classificação etária está para maiores de 4 anos de idade.

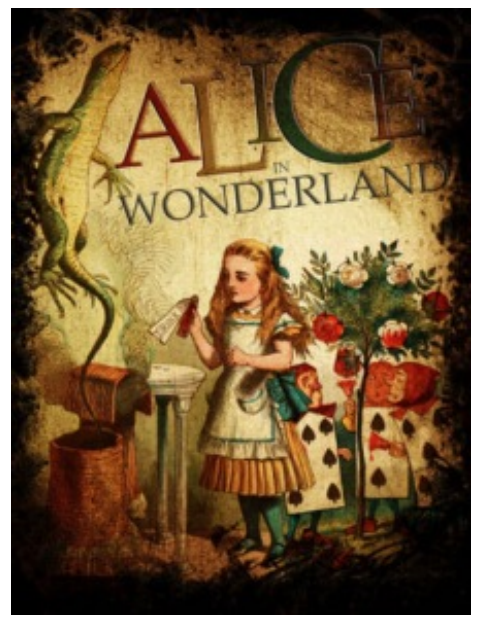

(a)

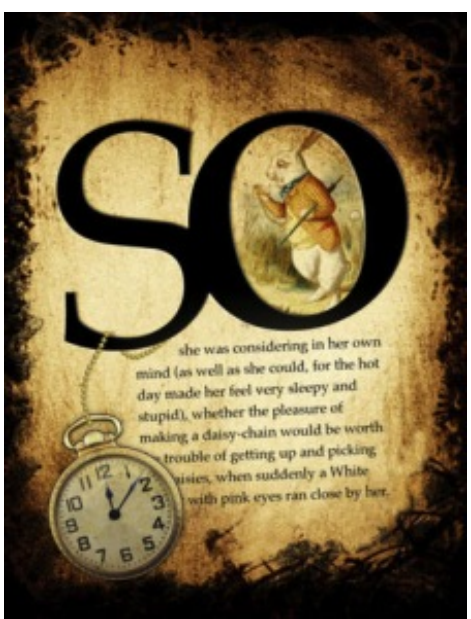

(b)

Figura 1 - Capa do aplicativo e página onde é possível balançar o relógio de bolso do Coelho Branco. Fonte: App Store.

\subsubsection{Contos para crianças - PequeClássicos}

Desenvolvido por Susaeta, este aplicativo é descrito na App Store como um aplicativo voltado animar e estimular a leitura das crianças e transportá-los para um mundo de fantasia, estimulando a imaginação e o pensamento. É relatado ainda que o mesmo está disponível em cinco idiomas: português do Brasil, inglês, francês, italiano e espanhol; e traz em seu acervo as histórias de: Bambi, Branca de Neve, Peter Pan, Pinóquio e $O$ livro da selva. A produtora o descreve como uma versão animada, tátil e interativa desses livros, para que o usuário desfrute dos mesmos, participando das cenas juntamente aos personagens.

Ao analisar o aplicativo nota-se as seguintes características: o mesmo apresenta de início uma estante onde expõe seu acervo, e que demonstra ao usuário possuir, não só os títulos indicados em sua descrição, mas o adicional da história de 'Cinderela', sendo sua estante assim composta por 6 títulos. $O$ que não se referencia na descrição é o fato de somente uma da histórias estar disponível gratuitamente como modo de degustação do aplicativo, no caso do aplicativo utilizado para análise, a única história gratuita era 'Bambi', como podemos ver na Figura 2. Assim, as outras histórias estão disponíveis para compra individual ou em pacote.

Passando ao manuseio do aplicativo, este se mostra bem interessante, pois realmente demonstra maior interatividade entre o usuário e o aplicativo. Nele já em 
sua interface inicial, onde expõe seu acervo, coloca uma estante com perspectiva de profundidade, música instrumental relacionada ao motivo da aplicação e apresenta elementos em movimento, como borboletas que ficam batendo as asas na tela e ao serem clicadas saem voando. Ao clicar um dos livros o usuário é transportado para uma outra página, onde se dá início a história, aqui passa a se ter mais elementos com movimentos e cliques que podem fazer parar um animal, rodá-lo, fazê-lo mudar de posição ou direção, ou ainda, clicar múltiplas vezes em um elemento e fazê-lo estourar se transformando em diversas estrelas dispersas na tela.

$\mathrm{O}$ aplicativo ainda conta com a história disposta em forma de texto na tela e uma narração do mesmo, o que o torna acessível às necessidades do usuário. Também apresenta um menu oculto para auxílio durante a navegação e a disponibilidade de linguagem exposta pela sua desenvolvedora, porém seu recurso para troca de páginas se dá através de setas nos cantos inferiores esquerdo e direito das mesmas. Está presente em todas as páginas a perspectiva de profundidade utilizada em sua interface inicial.

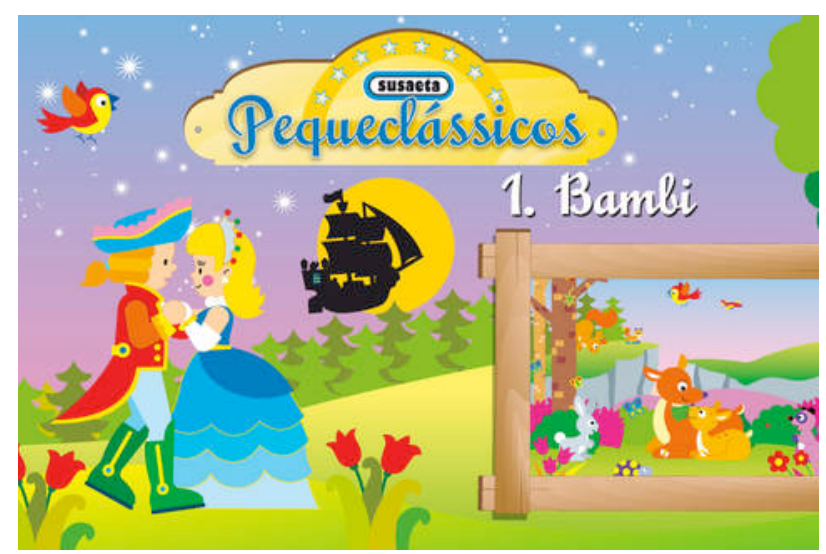

Figura 2 - Capa da história disponibilizada gratuitamente pelo aplicativo que se referencia ao clássico Bambi.

Fonte: App Store.

O mesmo também expõe um problema de compatibilidade, pois somente está disponível para os dispositivos da Apple, como: iPhone, iPad ou iPod touch. Ele também requer o iOS 4.3 ou posterior.

Apesar do fato da maioria das histórias estarem dispostas com um valor de custo e o problema de compatibilidade, o aplicativo mostra que vale a pena o investimento para aqueles que já possuem o dispositivo e querem fazer uso por terem crianças em casa ou para uso lúdico em trabalho.

Segundo a fabricante, o aplicativo passou por sua última atualização em 04/02/2013, seu tamanho é de 72,1 Mb e sua classificação etária, assim como o Alice for the IPad, está para maiores de 4 anos de idade.

\subsubsection{Doutor W: El misterioso caso del sentido extraviado}

Desenvolvido pela PIPILAPPS S.L., em sua descrição na App Store, "Doutor W: El misterioso caso del sentido extraviado" é exposto como um livro interativo e um aplicativo em dispositivo móvel, certificado pelo Programa Selo KidSafe ${ }^{\circledR}$, que é um serviço de certificação independente e um programa de selo que analisa e certifica as práticas de segurança de crianças no uso de sites e aplicações, incluindo sites 
direcionados garoto-jogo, os mundos virtuais, redes sociais, PC e aplicativos móveis, dispositivos conectados à Web e outros produtos on-line e interativos semelhantes. A empresa coloca ainda que o aplicativo está em sua versão 1.0.4, atualizada em 07/02/2014, tendo um tamanho de 40,4 Mb.

Este aplicativo propõe uma aventura em busca de resolver mistérios que estão acontecendo, ou seja, o livro se torna uma espécie de jogo onde você terá que ajudar - médico a encontrar elementos que faltam nas páginas e que desapareceram misteriosamente. $E$, com a contribuição ativa do usuário em todas as páginas, pode-se saber mais sobre os sentidos do corpo humano, o que o coloca como um aplicativo voltado ao sensorial.

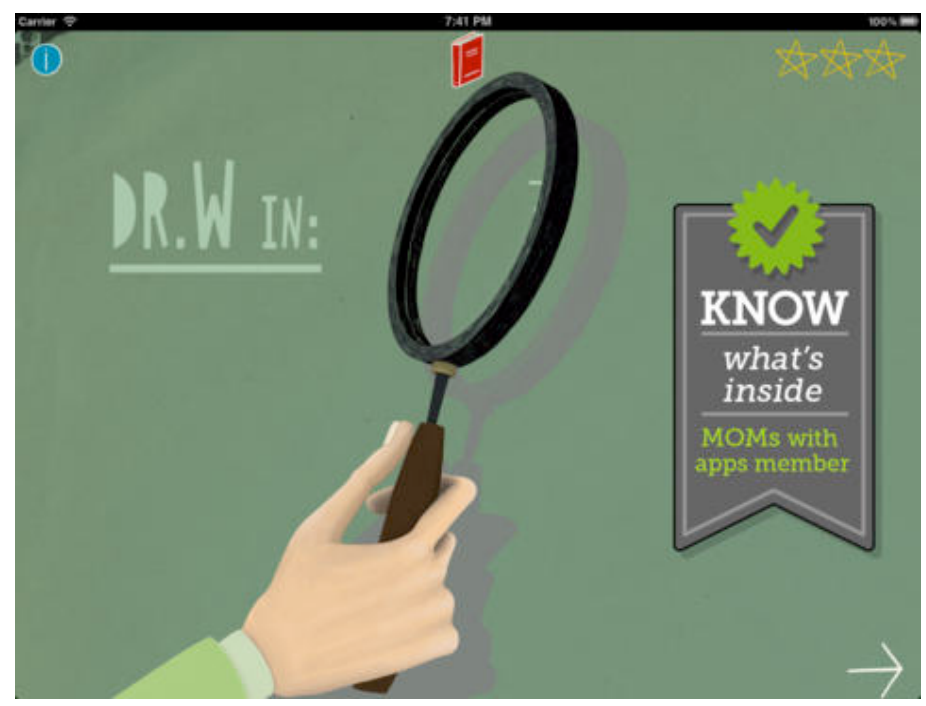

Figura 3 - Capa do aplicativo Doutor W: El misterioso caso del sentido extraviado que apresenta uma lupa como elemento a ser movimentado para descoberta de novos elementos que compõem a cena. Fonte: App Store.

Ao manusear o aplicativo observa-se já na interface inicial os elementos já trazem a interação entre usuário-aplicativo, onde é necessário movimentar com o arrastar dos dedos elementos que compõem a cena, ou até a própria cena, para descobrir novos elementos, como acontece com essa lupa exposta na Figura 3, e assim pontuar os elementos que faltam através de estrelas dispostas no canto superior direito da imagem, para poder mudar de página no aplicativo. Além dos elementos escondidos que devem ser encontrados na cena, o aplicativo possui uma música temática constante e balões de conversação, que também podem constar como elementos a serem descobertos.

Está presente em todas as páginas a perspectiva de profundidade utilizada em sua interface inicial e seu recurso para troca de páginas também se dá através de setas nos cantos inferiores esquerdo e direito das mesmas, como ocorre no aplicativo analisado anteriormente. Pode se notar que a interface deste aplicativo é semelhante com a de uma história em quadrinhos.

Infelizmente o aplicativo "Doutor W: El misterioso caso del sentido extraviado", traz consigo a falta de disponibilidade em mais idiomas, pois somente apresenta-se em catalão, espanhol ou inglês; a falta da narrativa da história; e, o que acontece com os demais aplicativos acima analisados, que é a sua disponibilidade somente para os dispositivos da Apple, neste caso o iPad; e também requerer o iOS 5.0 ou posterior. 


\subsection{Aplicativos disponíveis no Galaxy Tab 210.1 (Samsung)}

\subsubsection{Lá vem história - Histórias infantis}

O aplicativo, Lá vem história - Histórias infantis, que não possui um desenvolvedor identificado, é descrito na loja (Play Store) como: 'A mais completa aplicação em língua portuguesa sobre histórias infantis ilustradas, para crianças de todas as idades, inclusive em fase de alfabetização.

Consta ainda que a aplicação contém: 1. Histórias infantis; 2. Contos infantis; 3. Histórias para crianças; 4. Histórias e contos para dormir; 5. Fábulas e historinhas; e, 6. Crônicas infantis. Apresenta ainda um quesito Novidades, onde relata que em sua atualização, realizada 01/04/2014, para a versão 2.0 aconteceu: uma correção de bugs, menos conteúdo de publicidade e melhora da interface. Com tamanho de 2,19 Mb e classificação de conteúdos voltada a baixo nível de maturidade.

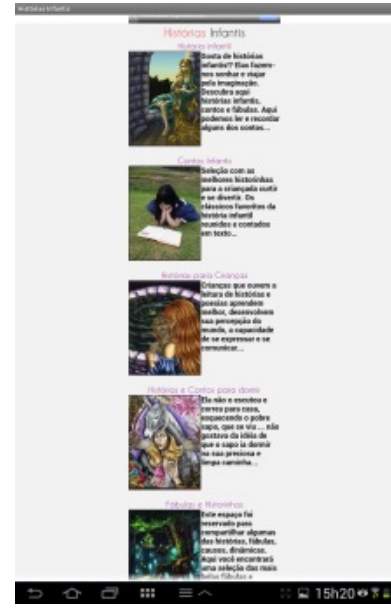

(a)

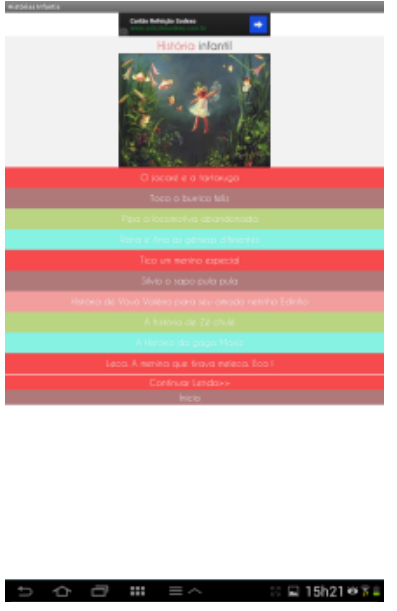

(b)

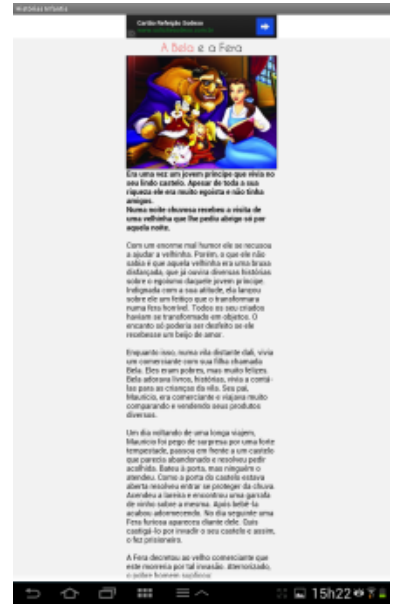

(c)

Figura 4 - Interfaces do aplicativo Lá vem história - Histórias infantis.

Fonte: Elaborada pelo autor, com base na pesquisa realizada.

Nele encontramos interfaces fixas, sendo a primeira com um menu de entrada elaborado com imagens dispostas em lista com a descrição lateral que classifica o conteúdo disponível no acervo do aplicativo, como pode ser visto na Figura 4a. Ao clicar em uma das imagens acessamos outro menu que nos mostra os títulos literários disponíveis na biblioteca deste aplicativo, como demonstrado na Figura 4b, e ao selecionarmos o título, abre uma nova página com o texto literário (conto, fábula ou crônica), como apresentado na Figura 4c. O que se pode observar no aplicativo são interfaces disponibilizadas de forma fixa na tela do dispositivo e que não proporciona maiores interações com o usuário.

\subsubsection{Contos BR Droid vol.1 - Chapeuzinho Vermelho}

A desenvolvedora Moonjava disponibiliza na loja diversos aplicativos, cada um com uma história diferente, que são diferenciados através de volumes; porém, neste estudo, o aplicativo analisado é o 'Chapeuzinho Vermelho BR Droid vol.1', por estar melhor classificado, segundo a Play Store.

A Moonjava ao descrever seu aplicativo afirma que o mesmo é "O melhor aplicativo de contos infantis do Brasil", que "Milhares de crianças já se divertiram com 
este aplicativo', que a 'História é $100 \%$ gratuita' e que o conto infantil apresenta-se na língua portuguesa. Aponta ainda que o aplicativo conta com: ilustrações do conto infantil; narração de toda a história em português, e cada personagem com uma voz diferente; textos; e, perguntas e respostas do entendimento da história. A empresa afirma ainda em sua descrição que este conto possui todas as páginas animadas, deixando a criança mais esperta e feliz.

É divulgado pela desenvolvedora que última melhora realizada no aplicativo aconteceu em sua versão 1.1.3, relacionado a melhorias de som, apesar do mesmo está atualmente em sua versão 1.1.6, atualizado em 31/12/2013. Este aplicativo apresenta o tamanho de $30,04 \mathrm{Mb}$ e classificação de conteúdos voltada a baixo nível de maturidade.

Analisando o aplicativo podemos notar que sua primeira interface já direciona o mesmo ao título da história (livro), neste caso 'Chapeuzinho Vermelho'. Após esta primeira fase, colocada como capa do livro, o aplicativo traz as seguintes características: troca de páginas através do folheamento, narrações em primeira e terceira pessoa e adicional de músicas ao decorrer da história.

Apesar de trazer um dos melhores recursos de troca de página, onde possibilita ao usuário mudar de página como se estivesse mudando a página de um livro impresso, se equiparando ao Alice for the IPad com visual clássico da história, com suas páginas e ilustrações que imitam as produções literárias antigas impressas em papel, como pode ser visto na Figura 6.

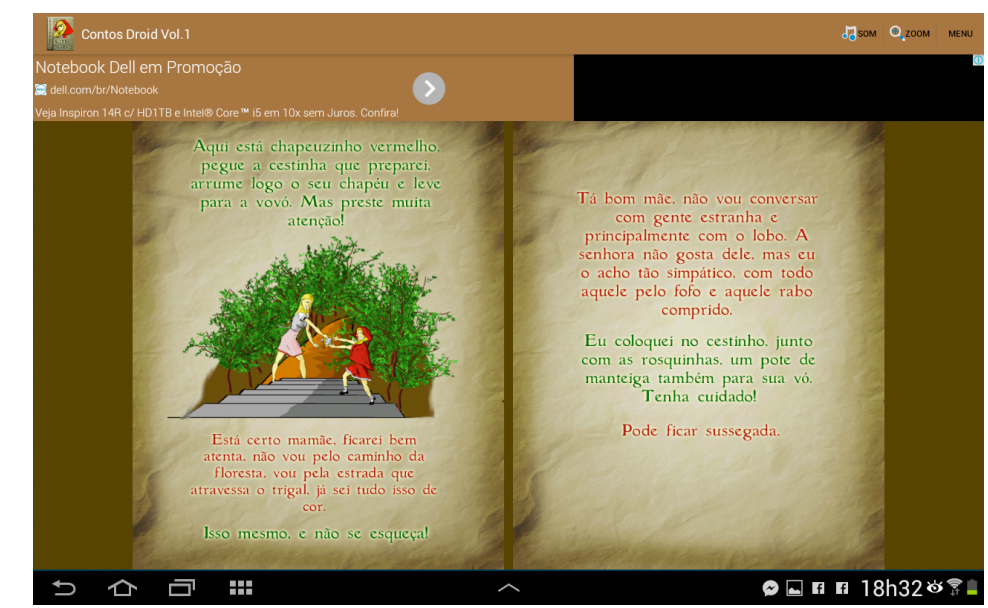

Figura 5 - Interface do aplicativo Contos BR Droid vol.1 - Chapeuzinho Vermelho.

Fonte: Elaborada pelo autor, com base na pesquisa realizada.

Infelizmente o mesmo não apresenta elementos que provocam a interação entre aplicativo e o usuário, o que o torna estático e não instigante diante o leitor/usuário.

\subsubsection{Histórias infantis}

Desenvolvido por Apeiron Informática, este aplicativo, em sua versão 1.3, atualizada em 27/02/2014, apresenta em sua descrição, que o mesmo contém as mais populares histórias infantis, que as histórias estão disponíveis em desenho animados e algumas com narração. O conteúdo apresentado seria: Os Três Porquinhos, Chapeuzinho Vermelho, Cinderela, Branca de Neve, A Bela Adormecida e muitos outros. Faz ainda uma observação: 'Este aplicativo necessita de internet para exibir os 
vídeos. / Caso seu aplicativo não tenha o player do YouTube, baixe o player primeiro'. E coloca como novidade do aplicativo uma correção do problema do player do YouTube. Apresenta tamanho de $480 \mathrm{~Kb}$ e classificação de conteúdos voltada a baixo nível de maturidade.

A exemplo do aplicativo 'Lá vem história - Histórias infantis', neste aplicativo também encontramos interfaces fixas, tendo na primeira somente um botão de entrada para uma lista de histórias, o que pode ser visto na Figura 6a, porém é o único encontrado durante a pesquisa que apresenta um breve conceito sobre 'o que são contos?' e 'o que são fábulas?', se faz importante essa distinção de significado entre os tipos de histórias, pois muitas vezes um usuário desconhece as diferenças de cada uma.

Após essa tela inicial e ao clicar o botão que te leva ao acervo de histórias, como podemos observar na Figura $6 \mathrm{~b}$, se descobre que a biblioteca não é tão vasta quanto relatada na descrição do produto, pois além das histórias já citadas, existem somente mais cinco títulos, sendo estas: João e Maria, Pinóquio, A Bela e a Fera, A pequena sereia e Peter Pan; o que pode causar uma certa insatisfação ao usuário.

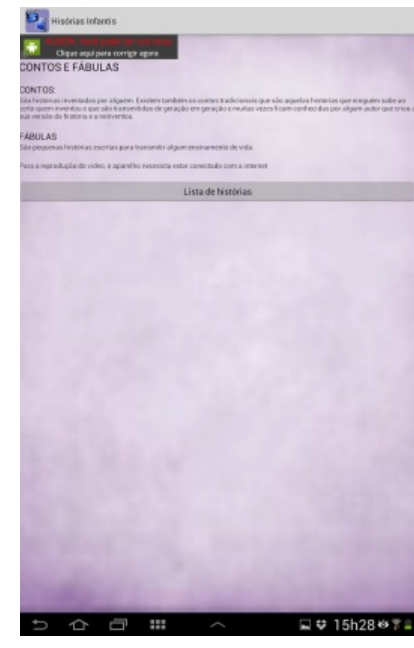

(a)

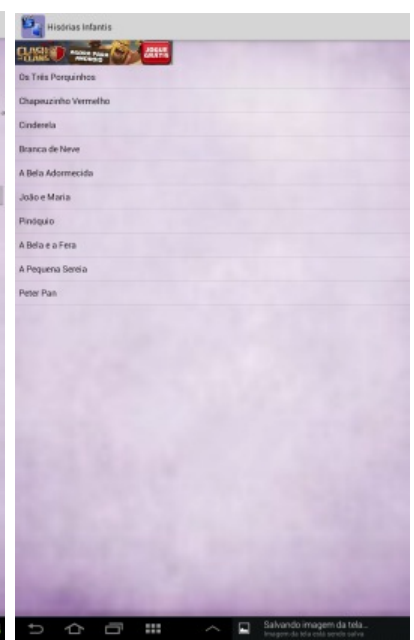

(b)

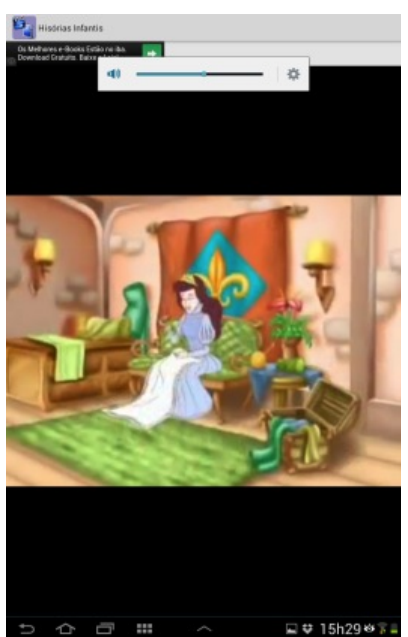

(c)

Figura 6 - Interfaces do aplicativo Histórias infantis.

Fonte: Elaborada pelo autor, com base na pesquisa realizada.

Passada a experiência da disposição, em lista, dos títulos das histórias, que servem como botão de entrada a navegação no aplicativo, o que se encontra são desenhos animados clássicos disponibilizados através do site Youtube, como se pode analisar na Figura $6 \mathrm{c}$; ou seja, não há uma interação disponibilizada pelo desenvolvedor entre o aplicativo e o usuário a não ser o fato do mesmo poder assistir desenhos, o que poderia ser realizado de outra forma, como por exemplo, utilizando o aplicativo do próprio Youtube para a atividade. Assim, o aplicativo serve apenas como uma busca rápida a estas histórias infantis na rede do YouTube.

\section{PADRÕES DE INTERAÇÃO}

Nos aplicativos analisados no decorrer deste estudo, foram encontrados padrões de interação, que compõem suas interfaces. Na tabela 1 podemos analisar os padrões de interação encontrados nos aplicativos, fazendo um registro de suas causas e efeito. 
Tabela 1 - Registro de padrões de interação encontradas nos aplicativos

\begin{tabular}{ll}
\hline Causa & Efeitos \\
\hline Toque & $\begin{array}{l}\text { Reprodução de sons, execução de movimento, troca de } \\
\text { páginas }\end{array}$ \\
\hline Gestos & Mudanças de páginas \\
\hline Acelerômetro & Interação com elementos de composição \\
\hline
\end{tabular}

Fonte: Elaborado pelo autor, com base na pesquisa realizada.

O quadro 1, por sua vez, expõe um comparativo de características, dados e padrões interativos encontrados nos aplicativos analisados neste estudo.

Quadro 1 - Comparativo de dados nos Aplicativos

\begin{tabular}{|l|c|c|c|c|c|c|}
\hline CARACTERÍSTICAS & $\begin{array}{c}\text { Alice for } \\
\text { the IPad }\end{array}$ & $\begin{array}{c}\text { Contos } \\
\text { para } \\
\text { Crianças }\end{array}$ & $\begin{array}{c}\text { Doutor } \\
\text { W }\end{array}$ & $\begin{array}{c}\text { Lá vem } \\
\text { história }\end{array}$ & $\begin{array}{c}\text { Contos BR } \\
\text { Droid } \\
\text { vol.1 }\end{array}$ & $\begin{array}{c}\text { Histórias } \\
\text { infantis }\end{array}$ \\
\hline Toque & Sim & Sim & Sim & Sim & Sim & Sim \\
\hline Acelerômetro & Sim & Não & Não & Não & Não & Não \\
\hline Gestos & Sim & Sim & Sim & Não & Sim & Não \\
\hline $\begin{array}{l}\text { Elementos } \\
\text { interativos }\end{array}$ & Sim & Sim & Sim & Não & Não & Não \\
\hline $\begin{array}{l}\text { Perspectiva de } \\
\text { Profundidade }\end{array}$ & Sim & Sim & Sim & Não & Não & Não \\
\hline $\begin{array}{l}\text { Troca de página } \\
\text { por folheamento }\end{array}$ & Sim & Não & Não & Não & Sim & Não \\
\hline $\begin{array}{l}\text { Troca de páginas } \\
\text { por setas }\end{array}$ & Não & Sim & Sim & Sim & Não & Não \\
\hline Propagandas & Não & Não & Não & Sim & Sim & Sim \\
\hline Vídeo & Não & Não & Não & Não & Não & Sim \\
\hline Comando de Voz & Não & Não & Não & Não & Não & Não \\
\hline Narração & Não & Sim & Não & Não & Sim & Não \\
\hline Texto & Sim & Sim & Sim & Sim & Sim & Não \\
\hline Tamanho Kb/Mb & $41,0 M b$ & $72,1 M b$ & $40,4 M b$ & $2,19 M b$ & $30,04 M b$ & $480 K b$ \\
\hline $\begin{array}{l}\text { Sistema } \\
\text { Operacional }\end{array}$ & iOS & iOS & iOS & Android & Android & Android \\
\hline
\end{tabular}

Fonte: Elaborado pelo autor, com base na pesquisa realizada.

\section{CONCLUSÃO}

Com o presente estudo podemos analisar que a partir do conceito de storytelling e sua colocação no momento atual, podemos abarcar diversas formas de divulgação das histórias interativas, tornando interessante ligá-las à plataformas de reassistência, como: smart TV, smartphones e em especial tablets, que estão a cada dia mais acessíveis à população. 
Porém, com base nesta breve pesquisa realizada, nota-se que ainda há muito a ser rever e renovar com relação ao conteúdo, características, dados e padrões interativos a serem introduzidos em aplicativos do gênero, pois com a análise se tornou perceptível a deficiência e dificuldade do desenvolvedores no que se relaciona a interação com os usuários. Colocando em tabela e quadro comparativo, poucos foram os tipos de interações encontrados, somente três: toque, gestos e acelerômetro; e houve uma grande diferença de características entre os aplicativos.

A partir do que foi analisado com o estudo, pode-se concluir que para um posterior desenvolvimento de uma ferramenta de autoria para criação desse tipo de aplicativo voltado à storytellings, há a necessidade de realizar um maior levantamento bibliográfico de aplicativos do gênero, com considerações de usuários que os utilizam os mesmos, levando em consideração suas opiniões diante as aplicações e os padrões interativos encontrados; além da definição da metodologia a ser utilizada para a criação da ferramenta.

Visando trabalho futuro propõe-se, além de um maior levantamento bibliográfico sobre storytellings e de aplicativos do gênero, desenvolver uma metodologia de categorização desse tipo de aplicativos levando em consideração seus aspectos semióticos e de sistema.

\section{REFERÊNCIAS}

. Lá vem História: Histórias Infantis. Google Play, 2014. Disponível na

internet por http em: <https://play.google.com/store/apps/details? id=appinventor.ai_eddecontenidosbr.Historias_Infantis>. Acesso em 22/04/2013.

ANTELOPE, Atomic. Alice for the iPad. Apple iTunes, 2010. Disponível na internet por http em: <https://itunes.apple.com/br/app/alice-for-the-ipad/id354537426? mt=8>. Acesso em 20/04/2013.

APEIRON INFORMATICA. Histórias Infantis. Google Play, 2014. Disponível na internet por http em: <https://play.google.com/store/apps/details?id=com.apeiron.historias>. Acesso em 25/04/2013.

COGO, Rodrigo Silveira. Da memória ao storytelling: em busca de novas narrativas organizacionais. 2012. 273 f. Dissertação (mestrado) - Escola de Comunicações e Artes da Universidade de São Paulo.

CONTOS STUDIOS. Chapeuzinho Vermelho BR Droid. Google Play, 2013. Disponível na internet por http em: <https://play.google.com/store/apps/details?id=br.com. moonjava.contosdroidfree>. Acesso em 22/04/2013.

FERRER, Julio Ignacio Garcia. Contos para crianças. Susaeta Ediciones, Apple iTunes, 2013. Disponível na internet por http em: <https://itunes.apple.com/br/app/contospara-criancas/id571333556?mt=8>. Acesso em 03/04/2013.

MASSAROLO, João Carlos. Storytelling Transmídia: Narrativa para multiplataformas. In: Dossiê o que é mídia afinal. São Paulo: Tríade, 2013. P. 335-347.

PIPILAPPS. Doctor W. Apple iTunes, 2014. Disponível na internet por http em: $<$ https://itunes.apple.com/us/app/doctor-w/id504187763?mt=8>. Acesso em 22/04/2013. 